\title{
Burnout in French General Practitioners: A Nationwide Prospective Study
}

\author{
Frédéric Dutheil ${ }^{1,2,3}$, , Lenise M. Parreira ${ }^{2}$, Julia Eismann ${ }^{4}$, François-Xavier Lesage ${ }^{5,6}$, David Balayssac ${ }^{7,8}{ }^{(0)}$, \\ Céline Lambert ${ }^{9}$, Maëlys Clinchamps ${ }^{1,2, *}$, Denis Pezet ${ }^{10,11}$, Bruno Pereira ${ }^{9}$ and Bertrand Le Roy ${ }^{12}$
}

check for updates

Citation: Dutheil, F.; Parreira, L.M.; Eismann, J.; Lesage, F.-X.; Balayssac, D.; Lambert, C.; Clinchamps, M.; Pezet, D.; Pereira, B.; Le Roy, B. Burnout in French General Practitioners: A Nationwide Prospective Study. Int. J. Environ. Res. Public Health 2021, 18, 12044. https://doi.org/10.3390/ ijerph182212044

Academic Editor: Paul B. Tchounwou

Received: 8 October 2021

Accepted: 15 November 2021

Published: 16 November 2021

Publisher's Note: MDPI stays neutral with regard to jurisdictional claims in published maps and institutional affiliations.

Copyright: (c) 2021 by the authors. Licensee MDPI, Basel, Switzerland. This article is an open access article distributed under the terms and conditions of the Creative Commons Attribution (CC BY) license (https:/ / creativecommons.org/licenses/by/ $4.0 /)$.
1 CNRS, LaPSCo, Physiological and Psychosocial Stress, University Clermont Auvergne, 63000 Clermont-Ferrand, France; fdutheil@chu-clermontferrand.fr

2 Preventive and Occupational Medicine, University Hospital of Clermont-Ferrand, 63000 Clermont-Ferrand, France; lparreira@chu-clermontferrand.fr

3 WittyFit, 63000 Clermont-Ferrand, France

4 Faculty of Medicine, Department of General Practitioner, University Clermont Auvergne, 63000 Clermont-Ferrand, France; julia.eismann@gmail.com

5 Laboratory Epsylon, Dynamic of Human Abilities \& Health Behaviors, University of Montpellier, 34000 Montpellier, France; fx-lesage@chu-montpellier.fr

6 Occupational and Preventive Medicine, University Hospital of Montpellier, 34000 Montpellier, France

7 INSERM U1107 NEURO-DOL, University Clermont Auvergne, 63000 Clermont-Ferrand, France; dbalayssac@chu-clermontferrand.fr

8 Clinical Research and Innovation Direction, University Hospital of Clermont-Ferrand, 63000 Clermont-Ferrand, France

9 Biostatistics Unit, Clinical Research and Innovation Direction, University Hospital of Clermont-Ferrand, 63000 Clermont-Ferrand, France; clambert@chu-clermontferrand.fr (C.L.); bpereira@chu-clermontferrand.fr (B.P.)

10 INSERM U1071, M2iSH, University Clermont Auvergne, USC-INRA 2018, 63000 Clermont-Ferrand, France; dpezet@chu-clermontferrand.fr

11 Department of Digestive Surgery, University Hospital of Clermont-Ferrand, 63000 Clermont-Ferrand, France

12 Department of General Surgery, University Hospital of Saint-Etienne, 42270 Saint-Priest-en-Jarez, France; leroybertrand8@gmail.com

* Correspondence: mclinchamps@chu-clermontferrand.fr

Abstract: Background: We aimed to evaluate the prevalence of burnout among French general practitioners in private practice and to study the risk and protective factors of burnout. Methods: A nationwide cross-sectional study was conducted with French GPs working in a private practice in France who were asked to fulfil an internet questionnaire. We used the secure internet application REDCap $^{\circledR}$. Exclusion criteria were only working in a hospital, substitute doctors, and internship students. There was a putative sample size of 88,886 GPs. We retrieved the Maslach Burnout Inventory (MBI), occupational characteristics (type of installation, emergency regulated shifts, night shifts, university supervisor, weekly hours worked, seniority), and personal characteristics such as age, gender, marital status, and number of children. Results: We included 1926 GPs among the 2602 retrieved questionnaires. A total of $44.8 \%$ of French liberal GPs were experiencing burnout, with $4.8 \%$ (95\%CI 3.9-5.9\%) experiencing severe burnout. The risk factors of severe burnout were male gender $(\mathrm{RR}=1.91,95 \% \mathrm{CI} 1.15-3.16)$, working in a suburban area $(5.23,2.18-12.58)$, and having more than 28 appointments per day $(1.95,1.19-3.19)$. Working more than $50 \mathrm{~h}$ weekly showed a tendency to increase the risk of severe burnout $(1.55,0.93-2.59, p=0.095)$, with a significant increase in the risk of low and moderate burnout $(1.31,1.02-1.67$ and $1.86,1.34-2.57$, respectively). Protective factors were mainly resident training, which decreased the risk of both low, moderate, and severe burnout $(0.65$, $0.51-0.83 ; 0.66,0.48-0.92$; and $0.42,95 \%$ CI $0.23-0.76$, respectively). Performing home visits decreased the risk of severe burnout $(0.25,0.13-0.47)$, as did group practice for intermediate level of burnout (0.71, 0.51-0.96). Conclusion: GPs are at a high risk of burnout, with nearly half of them in burnout, with burnout predominantly affecting males and those between the ages of 50 and 60 years old. The main risk factors were a high workload with more than 28 appointments per day or $50 \mathrm{~h}$ of work per week, and the main protective factors were related to social cohesion such having a teaching role and working in a group practice with back-office support. 
Keywords: mental health; burnout; general practitioners

\section{Introduction}

Several nationwide studies have demonstrated that General Practitioners (GPs) are particularly at risk of burnout. The high prevalence of burnout seems to be global in GPs, as demonstrated through nationwide studies from Europe [1-4], America [5], Asia [6,7], and Africa [8]. However, nationwide studies with a good representation of French GPs are lacking. Moreover, GP practice in France has some specificities, such as GPs total freedom in their mode of practice. Studying factors influencing burnout are of particular interest to build preventive effective strategies and to avoid its public health consequences. In addition to sociodemographic such as age [9-11], gender [10-12], and family status [12], some occupational characteristics are also known to be risk factors of burnout such as workload [11,13] and long work duration [12]. Similarly, GPs are also exposed to emergencies during night shifts, which can be particularly stressful [14-16] and can be linked with burnout [17]. However, there are some protective factors for burnout, such as working in a healthy environment $[18,19]$ and social cohesion [20]. For GPs, social cohesion can be related to more clinical interaction $[18,21]$ and less administrative tasks [11,12]. Despite being sometimes viewed as being time consuming, home visits could also represent a sense of engagement and a clinically rewarding sense [22]. Particularly, in France, there is also a framework that allows GPs to practice either in a solo or group cabinet $[11-13,20]$ and to tutor medical students and interns $[9,20]$, which can fuel a sense of social cohesion. Moreover, no studies quantified the risk of burnout while combining all of those risk and protective factors. European studies show that GPs in rural areas seem to be more affected by burnout symptoms than GPs in urban regions are $[9,11,12,20,21]$.

Therefore, the aim of this study was to evaluate the prevalence of burnout among French general practitioners in private practice and to determine the risk and protective factors of burnout.

\section{Methods}

\subsection{Study Design}

This nationwide cross-sectional study took place over six consecutive months before the start of the COVID-19 pandemic.

Volunteer GPs were asked to fulfil an internet questionnaire. The questionnaire was created in a multidisciplinary way (doctors, epidemiologists, biostatisticians, etc.) and was tested on ten doctors before generalized sending. The questionnaires were completed anonymously. The online questionnaire was diffused several times through the mailing lists of the National, Regional and Departmental Physicians Council, the Regional Union of healthcare workers (URPS) and was published in two social groups for physicians on social media (Facebook and Linkedin). We used the secure internet application REDCap ${ }^{\circledR}$ to build and manage the questionnaire, which was hosted by the University Hospital of Clermont-Ferrand. The study was reviewed and approved by the human ethics committees Sud-Est VI (Clinicaltrials.gov (acceaaed on 8 October 2021) NCT04242862).

\subsection{Participants}

To be included, the participants had to be general practitioners in a private practice in France. The exclusion criteria were only working in a hospital, substitute doctors, and internship students. According to the figures from the French Medical Council (CNOM), there was a putative sample size of 88,886 GPs in France (Figure 1). 


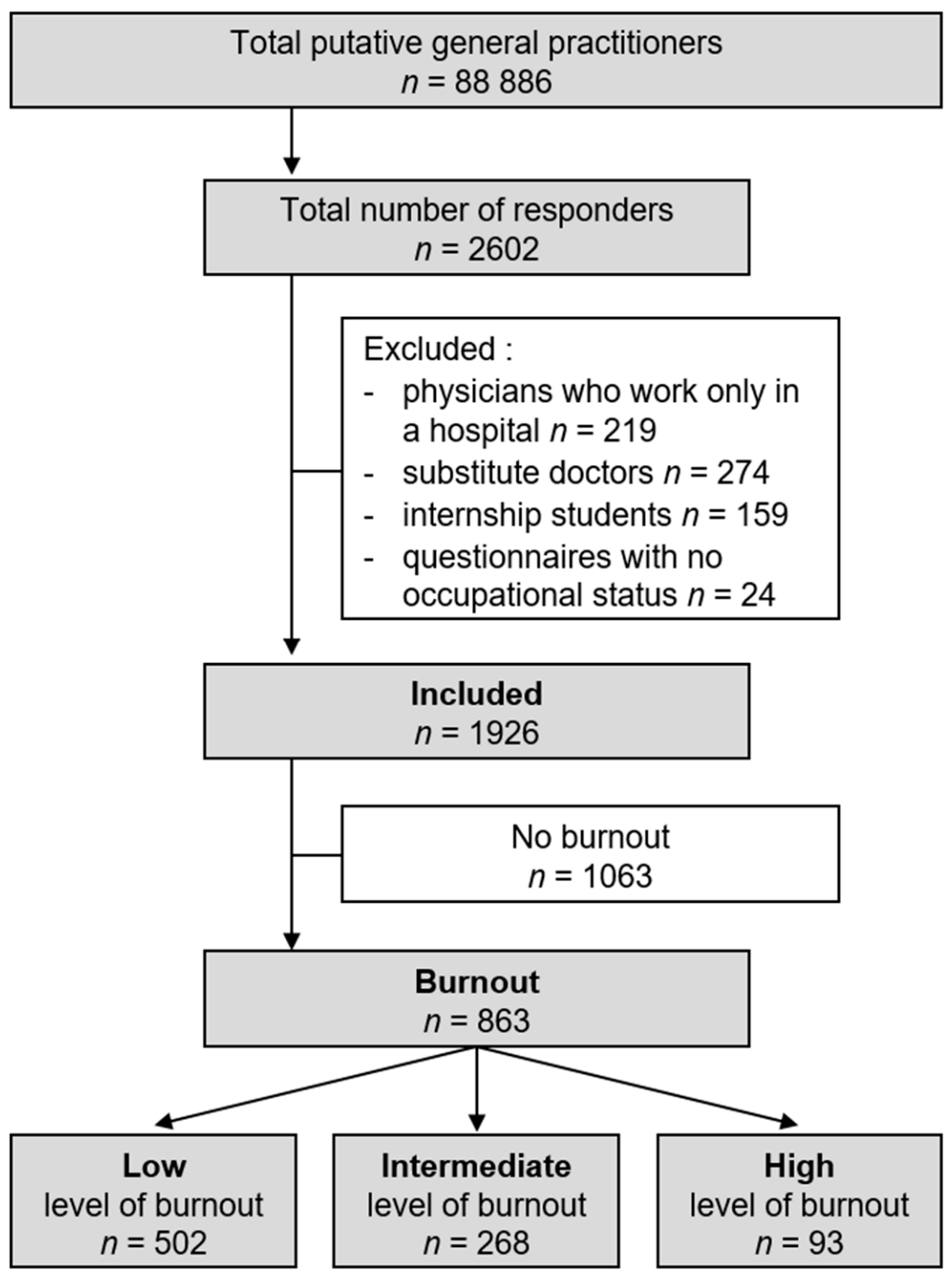

Figure 1. Flow chart.

\subsection{Instrument Survey-Outcomes}

\subsubsection{Burnout}

The Maslach Burnout Inventory (MBI) has demonstrated its external validity among GPs [23] and has been validated in French [24]. The MBI is composed of 22 items designed to assess the three dimensions of burnout syndrome: emotional exhaustion (9 items), depersonalization (5 items), and reduced personal accomplishment (8 items). The items are written in the form of statements concerning personal feelings or attitudes. Items are composed of a 7-point scale determining the frequency of feelings, with items varying from "never" to "every day". The scores for each dimension of burnout syndrome are considered separately and are not combined into a single total score. Scores for each dimension can be coded as low, average, or high. We considered that there was no burnout when all of the three dimensions report a low risk, low burnout when there was a high risk of burnout in one of the three dimensions, intermediate burnout when there was a high risk of burnout in two dimensions, and severe burnout when there was a high risk of burnout in the three dimensions [25].

\subsubsection{Occupational Characteristics}

We assessed career characteristics (career length, i.e., seniority within profession, and further qualifications such as specific complementary diplomas), setting characteristics 
(setting location - rural, suburban, or urban — and commuting time), social environment (group practice, home visits, and resident training as a university supervisor), work support (administrative support and partly salaried), workload (number of hours worked per week, and number of daily consultations), and emergency activity (yes/no, realisation of night emergency-regulated shifts in private practice, and night shifts in an emergency hospital department).

\subsubsection{Personal Characteristics}

Age, gender identity, marital status, and whether the participants had children were assessed.

\subsection{Statistics}

We estimated that the sample size should comprise at least 1536 individuals using an expected prevalence of severe burnout ranging between $10 \%$ and $20 \%$ from the EGPRN study [26], allowing us to highlight results with a $2 \%$ error margin for a $95 \%$ confidence level. All of the statistical analyses were performed with Stata ${ }^{\circledR}$ software (version 15, StataCorp, College Station, TX, USA). The categorical variables were described using frequencies and percentages, whereas the continuous variables were presented with mean \pm standard deviation or median (interquartile range) according to their statistical distribution. The normality was accessed using the Shapiro-Wilk test. Confidence intervals $(95 \% \mathrm{CI})$ for burnout prevalence according to the MBI were estimated using the exact binomial approach. Then, the comparisons of the burnout prevalence between groups were performed using the Chi2 or Fisher's exact tests for the categorical variables and by using ANOVA or the Kruskal-Wallis tests for quantitative variables. The assumption of homoscedasticity was analysed with Bartlett's test. When appropriate (omnibus $p$-value was less than 0.05), post hoc tests for two-by-two multiple comparisons were applied: Tukey-Kramer after ANOVA, Dunn after Kruskal-Wallis, and Marascuilo for categorical variables. The relationships between the quantitative variables were analysed using the Pearson or Spearman correlation coefficients by applying Sidak's type I error correction. Finally, multivariate analysis was conducted with covariates chosen according to their clinical relevance and to the univariate results. More precisely, ordinal polynomial regression (i.e., ordered logit models of dependent ordinal variable) was conducted. Particular attention was paid to the study of multicollinearity and interactions between covariates (1) studying the relationships between the covariates and (2) evaluating the impact of adding or deleting variables on a multivariate model. The results were expressed as relative-risks and 95\% confidence intervals $(95 \% \mathrm{CI})$, and forest plots were employed to present the results. A Sidak's type I error correction was applied to take into account multiple comparisons. Multivariate analysis was performed for 1802 patients (i.e., 124 (6.4\%) missing data). A sensitivity analysis was conducted to analyse the statistical nature of the missing data. A two-sided type I error of 5\% was applied for all statistical tests. As such, a difference was considered statistically significant when $p \leq 0.05$.

\section{Results}

We received 2602 questionnaires, with 1926 GPs matching the inclusion criteria, representing a response rate of $3.6 \%$ of the 56430 national GP population meeting the criteria (Figure 1).

\subsection{Burnout Prevalence}

According to the MBI, $44.8 \%$ of the French liberal GPs were experiencing burnout: $4.8 \%$ (95\%CI 3.9-5.9\%) had severe burnout (severe scores within the 3 dimensions), $13.9 \%$ (95\%CI 12.4-15.5\%) had intermediate burnout (scoring severe within two dimensions), and a quarter of them $(26.1 \%, 95 \%$ CI $24.1-28.1 \%)$ had a low level of burnout (severe scores within one dimension). About half had no severe burnout scores (55.2\%, 95\%CI 52.9-57.4\%), regardless of the dimension (Table 1 ). 
Table 1. Burnout by sociodemographic and occupational characteristics.

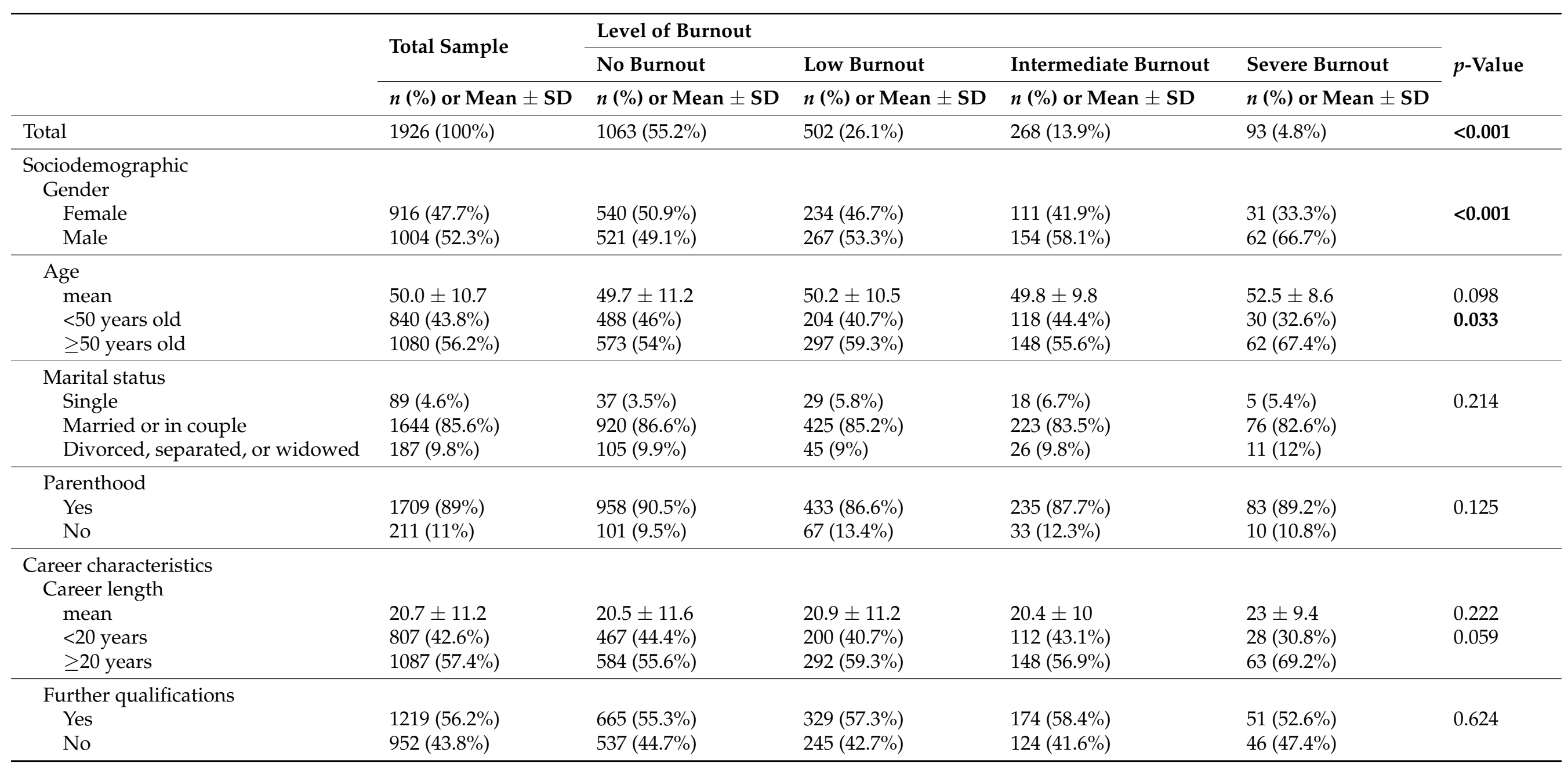


Table 1. Cont.

\begin{tabular}{|c|c|c|c|c|c|c|}
\hline & \multirow{3}{*}{$\begin{array}{l}\text { Total Sample } \\
n(\%) \text { or Mean } \pm \text { SD }\end{array}$} & \multicolumn{4}{|l|}{ Level of Burnout } & \multirow{3}{*}{$p$-Value } \\
\hline & & \multirow{2}{*}{$\begin{array}{l}\text { No Burnout } \\
n(\%) \text { or Mean } \pm \mathrm{SD}\end{array}$} & \multirow{2}{*}{$\begin{array}{l}\text { Low Burnout } \\
n(\%) \text { or Mean } \pm \mathrm{SD}\end{array}$} & \multirow{2}{*}{$\begin{array}{l}\text { Intermediate Burnout } \\
n(\%) \text { or Mean } \pm \mathrm{SD}\end{array}$} & \multirow{2}{*}{$\begin{array}{l}\text { Severe Burnout } \\
n(\%) \text { or Mean } \pm \mathrm{SD}\end{array}$} & \\
\hline & & & & & & \\
\hline \multicolumn{7}{|l|}{ Setting characteristics } \\
\hline \multicolumn{7}{|l|}{ Setting location } \\
\hline Rural & $427(22.3 \%)$ & $238(22.5 \%)$ & $113(22.7 \%)$ & $67(25.1 \%)$ & $9(9.7 \%)$ & 0.008 \\
\hline Suburban & $746(38.9 \%)$ & $398(37.6 \%)$ & $192(38.5 \%)$ & $103(38.6 \%)$ & $53(57 \%)$ & \\
\hline Urban & $743(38.8 \%)$ & $422(39.9 \%)$ & $193(38.8 \%)$ & $97(36.3 \%)$ & $31(33.3 \%)$ & \\
\hline \multicolumn{7}{|l|}{ Commuting time (min) } \\
\hline mean & $11.8 \pm 11.3$ & $11.3 \pm 10.5$ & $12.3 \pm 11.1$ & $12.8 \pm 14.1$ & $12.9 \pm 12.4$ & 0.088 \\
\hline$<12 \min$ & $1184(62.2 \%)$ & $668(63.5 \%)$ & $303(60.8 \%)$ & $156(59.1 \%)$ & $57(62 \%)$ & 0.527 \\
\hline$\geq 12 \min$ & $722(37.8 \%)$ & $384(36.5 \%)$ & $195(39.2 \%)$ & $108(40.9 \%)$ & $35(38 \%)$ & \\
\hline \multicolumn{7}{|l|}{ Social environment } \\
\hline \multicolumn{7}{|l|}{ Group practice } \\
\hline Yes & $1242(65.4 \%)$ & $725(69 \%)$ & $321(65.1 \%)$ & $151(56.6 \%)$ & $45(50.6 \%)$ & $<0.001$ \\
\hline No & $657(34.6 \%)$ & $325(31 \%)$ & $172(34.9 \%)$ & $116(43.4 \%)$ & $44(49.4 \%)$ & \\
\hline Yes & $1740(91.6 \%)$ & $970(92.4 \%)$ & $451(91.3 \%)$ & $248(92.9 \%)$ & $71(79.8 \%)$ & $<0.001$ \\
\hline No & $160(8.4 \%)$ & $80(7.6 \%)$ & $43(8.7 \%)$ & $19(7.1 \%)$ & $18(20.2 \%)$ & \\
\hline \multicolumn{7}{|l|}{ Resident training } \\
\hline Yes & $608(31.8 \%)$ & $384(36.4 \%)$ & $136(27.5 \%)$ & $71(26.8 \%)$ & $17(18.3 \%)$ & $<0.001$ \\
\hline No & $1300(68.2 \%)$ & $671(63.6 \%)$ & $359(72.5 \%)$ & $194(73.2 \%)$ & $76(81.7 \%)$ & \\
\hline \multicolumn{7}{|l|}{ Work support } \\
\hline \multicolumn{7}{|l|}{ Administrative support } \\
\hline Yes- on site or by phone & $1436(76.5 \%)$ & $813(78 \%)$ & $376(77.2 \%)$ & $183(70.1 \%)$ & $64(73.6 \%)$ & 0.050 \\
\hline No & $441(23.5 \%)$ & $229(22 \%)$ & $111(22.8 \%)$ & $78(29.9 \%)$ & $23(26.4 \%)$ & \\
\hline \multicolumn{7}{|l|}{ Partly salaried } \\
\hline Yes & $283(14.8 \%)$ & $162(15.3 \%)$ & $73(14.7 \%)$ & $34(12.7 \%)$ & $14(15 \%)$ & 0.755 \\
\hline No & $1632(85.2 \%)$ & $895(84.7 \%)$ & $424(85.3 \%)$ & $234(87.3 \%)$ & $79(85 \%)$ & \\
\hline
\end{tabular}


Table 1. Cont.

\begin{tabular}{|c|c|c|c|c|c|c|}
\hline & \multirow{3}{*}{$\begin{array}{l}\text { Total Sample } \\
n(\%) \text { or Mean } \pm \text { SD }\end{array}$} & \multicolumn{4}{|l|}{ Level of Burnout } & \multirow{3}{*}{$p$-Value } \\
\hline & & \multirow{2}{*}{$\begin{array}{l}\text { No Burnout } \\
n(\%) \text { or Mean } \pm \mathrm{SD}\end{array}$} & \multirow{2}{*}{$\begin{array}{l}\text { Low Burnout } \\
n(\%) \text { or Mean } \pm \mathrm{SD}\end{array}$} & \multirow{2}{*}{$\begin{array}{l}\text { Intermediate Burnout } \\
n(\%) \text { or Mean } \pm \mathrm{SD}\end{array}$} & \multirow{2}{*}{$\begin{array}{l}\text { Severe Burnout } \\
n(\%) \text { or Mean } \pm \mathrm{SD}\end{array}$} & \\
\hline & & & & & & \\
\hline \multicolumn{7}{|l|}{ Workload } \\
\hline \multicolumn{7}{|l|}{ Weekly hours } \\
\hline Mean & $50.6 \pm 12.4$ & $49.1 \pm 12$ & $51 \pm 11.9$ & $54.4 \pm 13.4$ & $53.7 \pm 13$ & $<0.001$ \\
\hline$<50 \mathrm{~h} /$ weeks & $805(41.9 \%)$ & $503(47.4 \%)$ & $196(39.1 \%)$ & $77(29 \%)$ & $29(31.5 \%)$ & $<0.001$ \\
\hline$\geq 50 \mathrm{~h} /$ weeks & $1115(58.1 \%)$ & $558(52.6 \%)$ & $305(60.9 \%)$ & $189(71 \%)$ & $63(68.5 \%)$ & \\
\hline \multicolumn{7}{|c|}{ Number of daily consultations } \\
\hline Mean & $28.6 \pm 11.1$ & $27.7 \pm 9.8$ & $28.9 \pm 10.3$ & $30.6 \pm 15.9$ & $32 \pm 10.5$ & $<0.001$ \\
\hline$<28$ consultations/day & $961(51.2 \%)$ & $569(54.7 \%)$ & $243(49.9 \%)$ & $117(45 \%)$ & $32(36 \%)$ & $<0.001$ \\
\hline$\geq 28$ consultations / day & $915(48.8 \%)$ & $471(45.3 \%)$ & $244(50.1 \%)$ & $143(55 \%)$ & $57(64 \%)$ & \\
\hline \multicolumn{7}{|l|}{ Emergency activity } \\
\hline \multicolumn{7}{|l|}{ Emergency work } \\
\hline Yes & $1166(60.9 \%)$ & $639(60.4 \%)$ & $309(62.2 \%)$ & $166(61.9 \%)$ & $52(55.9 \%)$ & 0.673 \\
\hline No & $750(39.1 \%)$ & $419(39.6 \%)$ & $188(37.8 \%)$ & $102(38.1 \%)$ & $41(44.1 \%)$ & \\
\hline Yes & $1033(88.9 \%)$ & $563(88.1 \%)$ & $278(90.3 \%)$ & $148(90.2 \%)$ & $44(86.3 \%)$ & 0.650 \\
\hline No & $129(11.1 \%)$ & $76(11.9 \%)$ & $30(9.7 \%)$ & $16(9.8 \%)$ & $7(13.7 \%)$ & \\
\hline \multicolumn{7}{|l|}{ Night shifts } \\
\hline Yes & $221(18.9 \%)$ & $121(18.9 \%)$ & $55(17.8 \%)$ & $32(19.3 \%)$ & 13 (25.5\%) & 0.638 \\
\hline No & $944(81.1 \%)$ & $518(81.1 \%)$ & $254(82.2 \%)$ & $134(80.7 \%)$ & $38(74.5 \%)$ & \\
\hline
\end{tabular}




\subsection{Burnout by Sociodemographic and Occupational Characteristics}

\subsubsection{Sociodemographic Variables}

From the 1926 samples that were obtained, about half were men $(52.3 \%, n=1004)$ (Figure 2). The mean global age was $50.0 \pm 10.7$ years, with the men being 8 years older than the women were on average (53.9 \pm 9.6 vs. $45.7 \pm 10.1, p<0.001)$. Both male GPs and those over the age of 50 years old were significantly more affected by severe burnout $(6.2 \%$ vs. $3.4 \%, p<0.001$ and $5.7 \%$ vs. $3.6 \%, p=0.033)$. Most of the respondents were married or in a couple $(85.6 \%, n=1644)$ and had children $(89.0 \%, n=1709)$, but none of those personal particularities influenced their risk of severe burnout. In addition to all of those risk factors of severe burnout, working more than $50 \mathrm{~h}$ per week was also a risk factor for low and moderate burnout.

\subsubsection{Career Characteristics}

More than half of the respondents had worked for more than 20 years $(57.4 \%$, $n=1087)$ and had acquired a supplementary qualification $(56.2 \%, n=1219)$, with male doctors having almost 10 more years of clinical experience $(24.8 \pm 10.4$ vs. $16.3 \pm 10.3$, $p<0.001)$ and a slightly higher prevalence of further qualifications than women $(48.1 \%$ vs. $43.8, p=0.063)$. Career length longer than 20 years almost emerged as a factor associated with severe burnout $(p=0.059)$. Benefiting from further qualifications was neither a risk factor nor a protective factor for burnout $(p=0.793)$. Results were similar through all burnout levels.

\subsubsection{Setting Characteristics}

Almost the same proportion of participants worked in urban or in suburban areas (38.8\% and $39.9 \%$, respectively), and only around $20 \%$ worked in rural areas (mostly males). Suburban physicians had a higher severe burnout rate than their rural or urban colleagues $(7.1 \%$ vs. $3.4 \%, p<0.001)$. The mean time spent during the journey from home to work was $12.0 \pm 11.3 \mathrm{~min}$ and was the same across burnout levels $(p=0.527)$.

\subsubsection{Social Practice Context}

The majority worked with other doctors in a group practice $(65.4 \%, n=1241)$, performed home visits $(91.6 \%, n=1740)$, and were invested in training a resident doctor $(31.8 \%, n=608)$, with a higher rate among rural practicians $(25.6 \%$ vs. $27.9 \%, p<0.001)$. All of those factors were related to a lower prevalence of severe burnout: $3.6 \%$ vs. $6.7 \%$ whether working in group or alone, $4.1 \%$ vs. $11.3 \%$ whether performing home visits or not, $2.8 \%$ vs. $5.9 \%$ whether training residents or not $(p<0.001)$.

\subsubsection{Work Support}

The GPs who had a secretariat $(76.5 \%, n=1436)$ showed a lower burnout rate (74.6\% vs. $78.1 \%, p=0.050)$, although working onsite or at home had no significant effect. Being an employee $(14.8 \%, n=283)$ was not related to the risk of burnout $(p=0.755)$. 


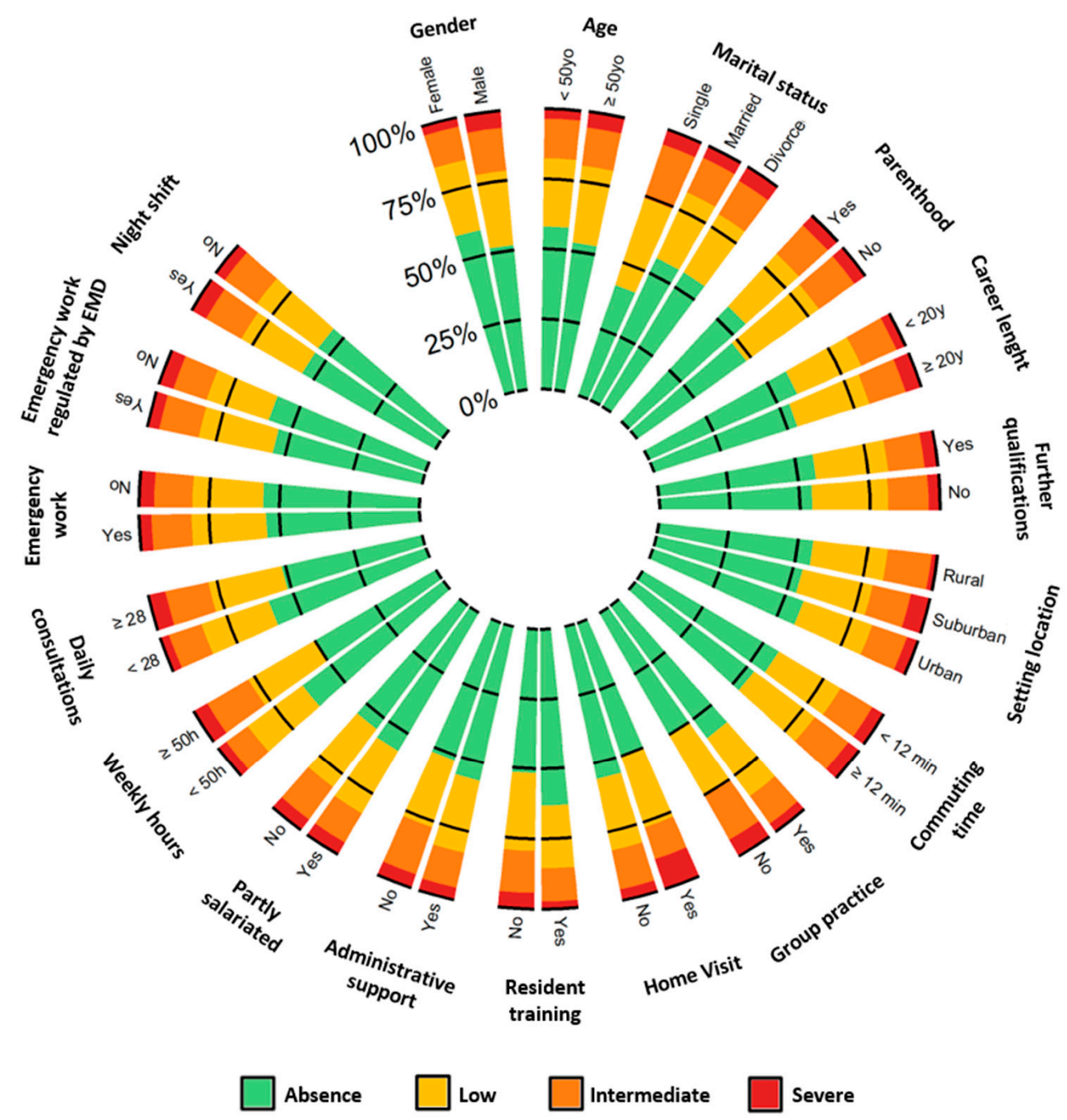

Figure 2. Polar histogram of levels of burnout depending on variables (see Supplementary Table S1 for details of percentages).

\subsubsection{Workload}

The GPs worked $50.5 \pm 12.4 \mathrm{~h}$ per week on average. The nearly $60 \%$ of the participants exceeding that amount had more severe burnout ( $5.7 \%$ vs. $3.6 \%, p<0.001)$; GPs with severe burnout also worked around $5 \mathrm{~h}$ more than those who were not experiencing burnout (53.7 \pm 12.9 vs. $49.1 \pm 12.1 \mathrm{~h}, p<0.001)$. GPs seeing more than the average of $28.5 \pm 11.1$ consultations per day had more severe burnout (64 vs. $48 \%, p=0.003)$. Men worked $8 \mathrm{~h}$ more than their women counterparts $(54.3 \pm 12.3$ vs. $46.4 \pm 11.0, p<0.001)$ and saw about five more patients per day $(30.9 \pm 12.6$ vs. $26.2 \pm 8.4, p<0.001)$.

\subsubsection{Emergency Activity}

Among the $60.9 \%(n=1166)$ of GPs who reported having emergency activity, $89.0 \%$ were regulated by the Emergency Medical Dispatch (EMD) (in private practice), and 18.9\% performed night shifts (in emergency departments). Performing shifts did not appear to be a risk factor for burnout $(p=0.673)$, whether they were regulated or not $(p=0.650)$.

\subsection{Relationships between Other Variables Than Burnout}

\subsubsection{Sociodemographic Variables}

The male GPs were statistically older (53.9 \pm 9.6 vs. $45.7 \pm 10.1$ for women, $p<0.001)$, had a longer career $(24.8 \pm 10.4$ vs. $16.3 \pm 10.3, p<0.001)$, were more likely to practice 
in group, have a secretariat, worked more hours, saw more patients, and had a lower commuting time $(p<0.001)$. On average, those who had children spent had a commute from home that was approximately 5 min shorter $(p<0.001)$.

\subsubsection{Setting Characteristics}

The suburban doctors had an overall similar workload to their urban colleagues, but and were more frequently associated with social practice characteristics, which were stated either as working in group practice, having a secretariat, or as performing home visits. A rural practice implied higher weekly working hours, daily appointment number, and more frequent resident training than the other settings, but it negatively correlated with emergency activities at night.

\subsubsection{Social Practice Context}

GPs completing home visiting worked more weekly hours than those who did not ( $50.8 \pm 12.0$ vs. $46.6 \pm 15.1, p<0.001)$ while keeping the same daily number of patients ( $28.6 \pm 10.8$ vs. $28.3 \pm 14.2, p=0.732$ ). Almost all of the rural and suburban doctors (respectively $98.1 \%$ and $95.3 \%$ ) performed home visits. In comparison, urban doctors performed less home visits than other groups $(84.1 \%, p<0.001)$. Less than a third were invested in training a resident doctor $(31.8 \%, n=608)$, with similar rates across the different geographical areas (urban: $30.9 \%$; suburban: $37.6 \%$; rural: $31.6 \%$ ). Intern tutoring was not associated with any geographical setup. All of those protective factors were more associated with suburban activity and less with rural activity. Regardless of the geographical area, the proportion of GPs with residents was the same. The doctors across different areas undertook a similar workload, which was evaluated either through weekly hours $(49.8 \pm 12.4$ vs. $50.5 \pm 12.4)$ or through daily consultations $(29.4 \pm 12.0$ vs. $28.6 \pm 10)$ (not significant).

\subsubsection{Work Support, Workload, and Emergency Activity}

GPs with a secretariat worked more frequently in a group practice $(87.8 \%$ vs. $12.2 \%$, $p<0.001)$, and worked less weekly hours $(p=0.04)$. Emergency activity, especially during the night was more frequent for males.

\subsection{Multivariate Analysis}

The risk factors of severe burnout were male gender $(R R=1.91,95 \% C I 1.15-3.16)$, working in a suburban area $(5.23,2.18-12.58)$, and having more than 28 appointments per day $(1.95,1.19-3.19)$ (Figure 3). Working more than $50 \mathrm{~h}$ weekly showed a tendency to increase the risk of severe burnout $(1.55,0.93-2.59, p=0.095)$, with a significant increase in the risk of low and moderate burnout (1.31, 1.02-1.67 and 1.86, $1.34-2.57$, respectively). Protective factors were mainly resident training which decreased the risk of both low, moderate, and severe burnout $(0.65,0.51-0.83 ; 0.66,0.48-0.92$; and $0.42,0.23-0.76$, respectively). Performing home visits decreased the risk of severe burnout $(0.25,0.13-0.47)$, as did group practice for the intermediate level of burnout $(0.71,0.51-0.96)$. 


\begin{tabular}{|c|c|c|c|}
\hline Variables & & Coefficient $(95 \% \mathrm{Cl})$ & $\begin{array}{c}\text { p- } \\
\text { value }\end{array}$ \\
\hline \multicolumn{4}{|l|}{ No burnout } \\
\hline & & Reference & \\
\hline \multicolumn{4}{|l|}{ Low burnout } \\
\hline Female & & $1.07(0.85,1.36)$ & 0.552 \\
\hline Suburban, rural as reference & & $1.01(0.75,1.35)$ & 0.982 \\
\hline Urban, rural as reference & - & $0.93(0.69,1.26)$ & 0.642 \\
\hline Resident training & & $0.65(0.51,0.83)$ & 0.001 \\
\hline$\geq 28$ daily consultations & & $1.15(0.91,1.45)$ & 0.247 \\
\hline$\geq 50$ weekly hours & $-\infty$ & $1.31(1.02,1.67)$ & 0.029 \\
\hline Administrative support & - & $0.97(0.73,1.29)$ & 0.849 \\
\hline Group practice & - & $0.95(0.74,1.24)$ & 0.726 \\
\hline Home visits & - & $0.79(0.52,1.21)$ & 0.286 \\
\hline \multicolumn{4}{|l|}{ Intermediate burnout } \\
\hline Female & & $1.16(0.86,1.57)$ & 0.319 \\
\hline Suburban, rural as reference & & $0.92(0.64,1.34)$ & 0.669 \\
\hline Urban, rural as reference & & $0.88(0.61,1.28)$ & 0.511 \\
\hline Resident training & & $0.66(0.48,0.92)$ & 0.013 \\
\hline$\geq 28$ daily consultations & $\infty_{-}$ & $1.23(0.92,1.65)$ & 0.168 \\
\hline$\geq 50$ weekly hours & & $1.86(1.34,2.57)$ & $<0.001$ \\
\hline Administrative support & - & $0.79(0.56,1.12)$ & 0.183 \\
\hline Group practice & & $0.71(0.51,0.96)$ & 0.031 \\
\hline Home visits & & $0.91(0.52,1.61)$ & 0.753 \\
\hline \multicolumn{4}{|l|}{ Severe burnout } \\
\hline Female & & $1.91(1.15,3.16)$ & 0.012 \\
\hline Suburban, rural as reference & 一 & $5.23(2.18,12.6)$ & $<0.001$ \\
\hline Urban, rural as reference & - & $2.12(0.83,5.38)$ & 0.115 \\
\hline Resident training & & $0.42(0.23,0.76)$ & 0.005 \\
\hline$\geq 28$ daily consultations & & $1.95(1.19,3.19)$ & 0.008 \\
\hline$\geq 50$ weekly hours & & $1.55(0.93,2.59)$ & 0.095 \\
\hline Administrative support & & $0.81(0.46,1.41)$ & 0.438 \\
\hline Group practice & & $0.67(0.41,1.11)$ & 0.124 \\
\hline Home visits & & $0.25(0.13,0.47)$ & $<0.001$ \\
\hline
\end{tabular}

Figure 3. Multivariate analysis with results expressed as relative risks (and 95\%CI). Bold $p$-value for significant risk or protective factor.

\section{Discussion}

The main findings of the present study are that we demonstrated a massive prevalence of burnout in GPs, with nearly half of them with some degree of burnout, predominantly affecting males and those between 50 and 60 years old. The main risks factors were working in suburban area, a high workload, which was defined as having more than 28 appointments per day, and male gender. The main protective factors were related to social cohesion, such having a teaching role and conducting home visits.

\subsection{Burnout Prevalence}

In our study, half of the GPs had some degree of burnout and were experiencing it in similar level of prevalence described in the literature [1-8,26-28]. Nevertheless, only $4.8 \%$ French liberal GPs were experiencing severe burnout, a much lower prevalence than those previously reported in similar nationwide studies $[27,28]$. This difference may be due to the French legal framework in which GPs operate. Indeed, GPs have the flexibility to organize their practice (work with or without a secretariat, interns, other colleagues, emergency activities, home visiting habits). Thus, they can organize their practice regarding determinants of burnout, such as workload, job control, effort rewards, community, fairness, and values $[13,20,25-28]$. Applying the framework of French legal specificities could reduce the prevalence of severe burnout among GPs in others countries [29]. A recent meta-analysis on burnout of French physicians that included 37 studies reported 
a similar prevalence of burnout $(48 \%)$, with $5 \%$ experiencing severe burnout [30]. No statistical difference has been found between other medical specialties, with the exception of emergency physicians, with $57 \%$ of them experiencing burnout and $12 \%$ experiencing severe burnout [30]. The mean prevalence of burnout in physicians is higher than in nonmedical professions [31]. However, meta-analysis on nurses including, 113 publications showed a high prevalence of severe burnout (11.2\%) [32]. Interestingly, the burnout rate in physicians seemed to increase with time [33,34], whereas a meta-analysis showed that suicide rate of physicians decreased over time, especially in Europe [35]. Burnout may also negatively affect patient care by increasing medical errors and decreasing productivity and empathy toward patients [36]. Physicians with burnout are twice as likely to deliver unsafe care, have unprofessional behavior, and cause patient unsatisfaction [37]. Burnout is also associated with a large number of physical, psychological, occupational, and social consequences, such as cardiovascular disease, musculoskeletal pain, alcohol consumption, obesity, sleep disorders, or dehumanization [38].

\subsection{Risk Factors}

We demonstrated that the main risk factors of burnout were to be a man, working in semi-rural areas, and have a high workload. As previously described in other studies [21,28], the risk of severe burnout in men was three times higher than in women. Men combined several risk factors, such as accepting high workloads [39] and working alone more often, without other GPs or a secretariat. In France, contrary to other European studies [9,10], older GPs had more burnout than younger ones. Previous GPs generations admitted to working closer to their limits [39] and thought of an early retirement [40]. Working nearby older colleagues experiencing burnout can discourage the recruitment and installation of young GPs [41]. The expectations that young doctors have about family life and work-life balance [42] might lead them to abandon the specialty [39,41,42]. Although not statistically different, single GPs present a higher burnout rate against those in a couple. Previous studies showed that marital status had a similar effect on on the burnout [39]. As expected, high burnout was more likely with a higher workload [27] but not among those who had worked during emergency activities, unlike what has been described in the literature $[27,28]$. As the amount of revenue that GPs make is tied to their number of consultations, they are prone to accept and deal with more patients $[43,44]$. In the literature, administrative tasks are also commonly described as a burden by GPs $[43,45]$. Transferring duties to staff members or having a secretariat increases office efficiency, patient satisfaction, productivity, and well-being $[46,47]$. Being a part-time employee in a health centre also allows social cohesion, less administrative tasks, and provides a fixed salary and social benefits [48]. However, it imposes the constraints of working in an enterprise, i.e., lower autonomy, imposed cadence and working methods [49], shared workspaces [12,20] and budget constraints [13,44].

\subsection{Protective Factors}

In our study, the main protective factors were those bringing a social cohesion [41], such as working in a group practice, having a teaching role, or the geographical area of practice. Group practice has also been previously described as a protective factor of burnout [48] — even if some studies did not find any influence [12,27,50]. Although some GPs do not usually seek their peers for advice-alleging lack of time-they recognize that clinical discussions solved during clinical discussions [21]. Encouraging peer arrangements should be a key intervention $[21,41,51]$, both within the specialty and with other specialists $[29,41]$. Group practice may also benefit the socials needs that physicians have. Similarly, resident training has been consistently associated with a GPs experiencing a lower burnout rate, as it seems to promote regular clinical interactions and therefore avoid isolation [27]. Through the distribution of tasks to their residents [21], they may also reduce their workload and may even improve their own technical skills [21,41]. For solo practitioners, resident training may also reduce the perception of isolation. Lastly, the geographical 
area of the practice influenced burnout in our study. In line with the literature [28,50], working in rural areas is a protective factor of burnout. Even though national rural areas have difficulties in recruiting doctors, they had a significantly lower burnout prevalence. This may be related to the greater satisfaction given by their relationship with patients, clinical autonomy, and life in small communities [2,12,27,49,51-54].

\subsection{Limitations and Strengths}

All of the limitations of the present study are followed by counterbalanced strengths. The main limitation is a cross-sectional study design; however, the primary aim was to report the prevalence of burnout in GPs, and this design allowed us to work with a large number of responses. Some councils and unions submitted less responses, which may have weakened geographical representativeness. The generalizability of our results may also be precluded by the high proportion of male respondents as well as general practitioners who are older than 50 years old. Furthermore, the French specificities of the practice of general medicine could prevent a generalization of results in other countries. Nevertheless, this is the first French nationwide study on GP burnout. We obtained a large sample size of respondents, allowing us to be confident in the accuracy of our data and giving us enough statistical power to study influencing factors with multivariate analysis. Our study is also one of the highest collections of burnout-related data in GPs compared to studies in other countries. It could have been interesting to compare the characteristics of the respondents and non-respondents; however, data were not available for the non-respondents, and other studies on GP burnout also lacked those comparisons. GPs prone to burnout might have been more prone to answer the questionnaire, inducing a selection bias, but this putative bias is common to any questionnaire-including all previous questionnaires concerning the prevalence of burnout among GPs from other countries [1-8]. The length of the questionnaire, due to the MBI scale and to diversity of factors explored, might have caused some GPs to refrain from responding. However, the MBI is a well-proven instrument, making comparisons with other studies possible. The comprehensive questionnaire also allowed us to retrieve data on our secondary outcomes, i.e., variables associated with burnout according to the literature. However, to guarantee the feasibility of a study with a short and relevant questionnaire, some missing variables that may have played an important role, have not been collected. For example, the work choice of GPs and their burnout rate may be related to income pressure, but this topic was not included. Our inclusion criteria were very strict, yet we had a homogeneous population of liberal GPs. The collection period of 6 months allowed a real screenshot of burnout at a specific time. Finally, it would be interesting to reproduce the study after the COVID-19 pandemic to evaluate the impact of the coronavirus pandemic on this front-line population [55-57].

\section{Conclusions}

General practitioners are at high risk of burnout, with nearly half of them experiencing burnout, predominantly affecting, especially those between 50 and 60 years old. The main risk factors for burnout were a high workload, and the main protective factors were related to social cohesion, such as having a teaching role and working in a group practice with backoffice support. Preventive strategies should be implemented to improve the well-being of general practitioners.

Supplementary Materials: The following are available online at https:/ / www.mdpi.com/article/10 .3390 /ijerph182212044/s1, Table S1: Burnout by sociodemographic and occupational characteristics (by $100 \%$ total in line). 
Author Contributions: Conceptualization: D.B. and B.L.; data curation: D.B. and B.P.; formal analysis: F.D., L.M.P., J.E., F.-X.L., D.B., C.L., M.C., D.P., B.P. and B.L.; investigation: J.E. and B.L.; methodology: F.D., D.B., B.P. and B.L.; project administration: J.E., D.B. and B.L.; writing-original draft: F.D., L.M.P. and M.C.; Writing-review and editing: F.D., L.M.P., J.E., F.-X.L., D.B., C.L., M.C., D.P., B.P. and B.L. All authors have read and agreed to the published version of the manuscript.

Funding: This research received no external funding.

Institutional Review Board Statement: The study was reviewed and approved by the human ethics committees Sud-Est VI (Clinicaltrials.gov (acceaaed on 8 October 2021) NCT04242862).

Informed Consent Statement: Informed consent was obtained from all subjects involved in the study.

Data Availability Statement: All relevant data were included in the paper.

Conflicts of Interest: The authors declare no conflict of interest.

\section{References}

1. Grassi, L.; Magnani, K. Psychiatric morbidity and burnout in the medical profession: An Italian study of general practitioners and hospital physicians. Psychother. Psychosom. 2000, 69, 329-334. [CrossRef]

2. Frutos-Llanes, R.; Jimenez-Blanco, S.; Blanco-Montagut, L.E. Burnout syndrome in general practitioners of Avila. Semergen 2014, 40, 357-365. [CrossRef] [PubMed]

3. Lesic, A.R.; Stefanovic, N.P.; Perunicic, I.; Milenkovic, P.; Tosevski, D.L.; Bumbasirevic, M.Z. Burnout in Belgrade orthopaedic surgeons and general practitioners, a preliminary report. Acta Chir. Iugosl. 2009, 56, 53-59. [CrossRef] [PubMed]

4. Fuchs, S.; Endler, P.C.; Mesenholl, E.; Pass, P.; Frass, M. Burnout in general practitioners. Wien. Med. Wochenschr. 2009, 159, 188-191. [CrossRef] [PubMed]

5. Roldan, A.; Barriga, Q. Burnout Syndrome, Family and Work Related Variables on General Practitioners in Bogota. A Strategy of Work Quality. Rev. Colomb. Psiquiatr. 2015, 44, 198-205.

6. Amiri, M.; Khosravi, A.; Eghtesadi, A.R.; Sadeghi, Z.; Abedi, G.; Ranjbar, M.; Mehrabian, F. Burnout and its Influencing Factors among Primary Health Care Providers in the North East of Iran. PLoS ONE 2016, 11, e0167648. [CrossRef]

7. Wang, Z.; Xie, Z.; Dai, J.; Zhang, L.; Huang, Y.; Chen, B. Physician burnout and its associated factors: A cross-sectional study in Shanghai. J. Occup. Health 2014, 56, 73-83. [CrossRef]

8. Liebenberg, A.R.; Coetzee Jnr, J.F.; Conradie, H.H.; Coetzee, J.F. Burnout among rural hospital doctors in the Western Cape: Comparison with previous South African studies. Afr. J. Prim Health Care Fam. Med. 2018, 10, e1-e7. [CrossRef]

9. Hirsch, O.; Adarkwah, C.C. The Issue of Burnout and Work Satisfaction in Younger GPs-A Cluster Analysis Utilizing the HaMEdSi Study. Int. J. Environ. Res. Public Health 2018, 15, 2190. [CrossRef]

10. O'Dea, B.; O'Connor, P.; Lydon, S.; Murphy, A.W. Prevalence of burnout among Irish general practitioners: A cross-sectional study. Ir. J. Med. Sci. 2017, 186, 447-453. [CrossRef]

11. Goehring, C.; Bouvier Gallacchi, M.; Kunzi, B.; Bovier, P. Psychosocial and professional characteristics of burnout in Swiss primary care practitioners: A cross-sectional survey. Swiss Med. Wkly. 2005, 135, 101-108. [PubMed]

12. Adarkwah, C.C.; Schwaffertz, A.; Labenz, J.; Becker, A.; Hirsch, O. Burnout and work satisfaction in general practitioners practicing in rural areas: Results from the HaMEdSi study. Psychol. Res. Behav. Manag. 2018, 11, 483-494. [CrossRef] [PubMed]

13. Edwards, S.T.; Marino, M.; Balasubramanian, B.A.; Solberg, L.I.; Valenzuela, S.; Springer, R.; Stange, K.C.; Miller, W.L.; Kottke, T.E.; Perry, C.K.; et al. Burnout Among Physicians, Advanced Practice Clinicians and Staff in Smaller Primary Care Practices. J. Gen. Int. Med. 2018, 33, 2138-2146. [CrossRef]

14. Dutheil, F.; Marhar, F.; Boudet, G.; Perrier, C.; Naughton, G.; Chamoux, A.; Huguet, P.; Mermillod, M.; Saâdaoui, F.; Moustafa, F.; et al. Maximal tachycardia and high cardiac strain during night shifts of emergency physicians. Int. Arch. Occup. Environ. Health 2017, 90, 467-480. [CrossRef]

15. Dutheil, F.; Trousselard, M.; Perrier, C.; Lac, G.; Chamoux, A.; Duclos, M.; Naughton, G.; Mnatzaganian, G.; Schmidt, J. Urinary interleukin-8 is a biomarker of stress in emergency physicians, especially with advancing age-The JOBSTRESS* randomized trial. PLoS ONE 2013, 8, e71658. [CrossRef] [PubMed]

16. Dutheil, F.; Boudet, G.; Perrier, C.; Lac, G.; Ouchchane, L.; Chamoux, A.; Duclos, M.; Schmidt, J. JOBSTRESS study: Comparison of heart rate variability in emergency physicians working a 24-hour shift or a 14-hour night shift-A randomized trial. Int. J. Cardiol. 2012, 158, 322-325. [CrossRef]

17. Stehman, C.R.; Testo, Z.; Gershaw, R.S.; Kellogg, A.R. Burnout, Drop Out, Suicide: Physician Loss in Emergency Medicine, Part I. West J. Emerg. Med. 2019, 20, 485-494. [CrossRef]

18. Branda, M.E.; Chandrasekaran, A.; Tumerman, M.D.; Shah, N.D.; Ward, P.; Staats, B.R.; Lewis, T.M.; Olson, D.K.; Giblon, R.; Lampman, M.A.; et al. Optimizing huddle engagement through leadership and problem-solving within primary care: A study protocol for a cluster randomized trial. Trials 2018, 19, 536. [CrossRef]

19. Harris, M.F.; Proudfoot, J.G.; Jayasinghe, U.W.; Holton, C.H.; Powell Davies, G.P.; Amoroso, C.L.; Bubner, T.K.; Beilby, J.J. Job satisfaction of staff and the team environment in Australian general practice. Med. J. Aust. 2007, 186, 570-573. [CrossRef] 
20. Wagner, E.H.; Flinter, M.; Hsu, C.; Cromp, D.; Austin, B.T.; Etz, R.; Crabtree, B.F.; Ladden, M.D. Effective team-based primary care: Observations from innovative practices. BMC Fam. Pract. 2017, 18, 13. [CrossRef]

21. Aira, M.; Mantyselka, P.; Vehvilainen, A.; Kumpusalo, E. Occupational isolation among general practitioners in Finland. Occup. Med. 2010, 60, 430-435. [CrossRef]

22. Magin, P.; Catzikiris, N.; Tapley, A.; Morgan, S.; Holliday, E.G.; Ball, J.; Henderson, K.; Elliott, T.; Regan, C.; Spike, N. Home visits and nursing home visits by early-career GPs: A cross-sectional study. Fam. Pract. 2017, 34, 77-82. [CrossRef] [PubMed]

23. Langballe, E.M.; Falkum, E.; Innstrand, S.T.; Aasland, O.G. The Factorial Validity of the Maslach Burnout Inventory-General Survey in Representative Samples of Eight Different Occupational Groups. J. Career Assess. 2006, 4, 370-384. [CrossRef]

24. Dion, G.; Tessier, R. Validation of a French translation of the Maslach Burnout Inventory (MBI). Can. J. Behav. Sci. 1994, 26, 210-227. [CrossRef]

25. Choron, G.; Dutheil, F.; Lesage, F.X. Are nurses burned out? Int. J. Nurs. Stud. 2016, 58, 80-81. [CrossRef]

26. Twellaar, M.; Winants, Y.; Houkes, I. How healthy are Dutch general practitioners? Self-reported (mental) health among Dutch general practitioners. Eur. J. Gen. Pract. 2009, 14, 4-9. [CrossRef]

27. Soler, J.K.; Yaman, H.; Esteva, M.; Dobbs, F.; Asenova, R.S.; Katić, M.; Ožvačić, Z.; Desgranges, J.P.; Moreau, A.; Lionis, C. Burnout in European family doctors: The EGPRN study. Fam. Pract. 2008, 25, 245-265. [CrossRef]

28. Galam, E.; Komly, V.; Le Tourneur, A.; Jund, J. Burnout among French GPs in training: A cross-sectional study. Br. J. Gen. Pract. 2013, 63, e217-e224. [CrossRef]

29. West, C.P.; Dyrbye, L.N.; Shanafelt, T.D. Physician burnout: Contributors, consequences and solutions. J. Int. Med. 2018, 283, 516-529. [CrossRef]

30. Kansoun, Z.; Boyer, L.; Hodgkinson, M.; Villes, V.; Lancon, C.; Fond, G. Burnout in French physicians: A systematic review and meta-analysis. J. Affect. Disord. 2019, 246, 132-147. [CrossRef]

31. Shanafelt, T.D.; Boone, S.; Tan, L.; Dyrbye, L.N.; Sotile, W.; Satele, D.; West, C.P.; Sloan, J.; Oreskovich, M.R. Burnout and satisfaction with work-life balance among US physicians relative to the general US population. Arch. Int. Med. 2012, 172, 1377-1385. [CrossRef]

32. Woo, T.; Ho, R.; Tang, A.; Tam, W. Global prevalence of burnout symptoms among nurses: A systematic review and meta-analysis. J. Psychiatr. Res. 2020, 123, 9-20. [CrossRef] [PubMed]

33. Shanafelt, T.D.; Hasan, O.; Dyrbye, L.N.; Sinsky, C.; Satele, D.; Sloan, J.; West, C.P. Changes in Burnout and Satisfaction With Work-Life Balance in Physicians and the General US Working Population Between 2011 and 2014. Mayo Clin. Proc. 2015, 90, 1600-1613. [CrossRef]

34. Matia Cubillo, A.C.; Cordero Guevara, J.; Mediavilla Bravo, J.J.; Pereda Riguera, M.J.; Gonzalez Castro, M.L.; Gonzalez Sanz, A. Evolution of burnout and associated factors in primary care physicians. Aten. Primaria 2012, 44, 532-539. [PubMed]

35. Dutheil, F.; Aubert, C.; Pereira, B.; Dambrun, M.; Moustafa, F.; Mermillod, M.; Baker, J.S.; Trousselard, M.; Lesage, F.X.; Navel, V. Suicide among physicians and health-care workers: A systematic review and meta-analysis. PLoS ONE 2019, 14, e0226361. [CrossRef]

36. Shanafelt, T.D.; Balch, C.M.; Bechamps, G.; Russell, T.; Dyrbye, L.; Satele, D.; Collicott, P.; Novotny, P.J.; Sloan, J.; Freischlag, J. Burnout and medical errors among American surgeons. Ann. Surg. 2010, 251, 995-1000. [CrossRef] [PubMed]

37. Panagioti, M.; Geraghty, K.; Johnson, J.; Zhou, A.; Panagopoulou, E.; Chew-Graham, C.; Peters, D.; Hodkinson, A.; Riley, R.; Esmail, A. Association Between Physician Burnout and Patient Safety, Professionalism, and Patient Satisfaction: A Systematic Review and Meta-analysis. JAMA Int. Med. 2018, 178, 1317-1330. [CrossRef]

38. Salvagioni, D.A.J.; Melanda, F.N.; Mesas, A.E.; Gonzalez, A.D.; Gabani, F.L.; Andrade, S.M. Physical, psychological and occupational consequences of job burnout: A systematic review of prospective studies. PLoS ONE 2017, 12, e0185781. [CrossRef]

39. Davidson, J.M.; Lambert, T.W.; Goldacre, M.J.; Parkhouse, J. UK senior doctors' career destinations, job satisfaction, and future intentions: Questionnaire survey. BMJ 2002, 325, 685-686. [CrossRef] [PubMed]

40. Heponiemi, T.; Kouvonen, A.; Vänskä, J.; Halila, H.; Sinervo, T.; Kivimäki, M.; Elovainio, M. Health, psychosocial factors and retirement intentions among Finnish physicians. Occupational medicine (Oxford, England). Occup. Med. 2008, 58, 406-412. [CrossRef]

41. Huby, G.; Gerry, M.; McKinstry, B.; Porter, M.; Shaw, J.; Wrate, R. Morale among general practitioners: Qualitative study exploring relations between partnership arrangements, personal style, and workload. BMJ 2002, 325, 140. [CrossRef]

42. Ballard, K.D.; Robinson, S.I.; Laurence, P.B. Why do general practitioners from France choose to work in London practices? A qualitative study. Br. J. Gen. Pract. 2004, 54,747-752. [PubMed]

43. Van Ham, I.; Verhoeven, A.A.H.; Groenier, K.H.; Groothoff, J.W.; De Haan, J. Job satisfaction among general practitioners: A systematic literature review. Eur. J. Gen. Pract. 2009, 12, 174-180. [CrossRef] [PubMed]

44. Nylenna, M.; Gulbrandsen, P.; Forde, R.; Aasland, O.G. Job satisfaction among Norwegian general practitioners. Scand. J. Prim. Health Care 2005, 23, 198-202. [CrossRef] [PubMed]

45. Simoens, S.; Scott, A.; Sibbald, B. Job satisfaction, work-related stress and intentions to quit of Scottish GPS. Scott. Med. J. 2002, 47, 80-86. [CrossRef]

46. Kuehn, B.M. To Fight Burnout, Cardiologists Look to Change Health System. Circulation 2018, 138, 836-837. [CrossRef]

47. Salzberg, L. Physician Well-Being: Improving Office Efficiency. FP Essent. 2018, 471, 16-19. 
48. Sturm, R. Effect of managed care and financing on practice constraints and career satisfaction in primary care. J. Am. Board. Fam. Pract. 2002, 15, 367-377.

49. Landon, B.E.; Reschovsky, J.; Blumenthal, D. Changes in career satisfaction among primary care and specialist physicians, 1997-2001. J. Am. Med. Assoc. 2003, 289, 442-449. [CrossRef]

50. Ulmer, B.; Harris, M. Australian GPs are satisfied with their job: Even more so in rural areas. Fam. Pract. 2002, 19, 300-303. [CrossRef] [PubMed]

51. Kinouani, S.; Boukhors, G.; Luaces, B.; Durieux, W.; Cadwallader, J.S.; Aubin-Auger, I.; Gay, B. Private or salaried practice: How do young general practitioners make their career choice? A qualitative study. BMC Med. Educ. 2016, 16, 231. [CrossRef]

52. Pathman, D.E.; Williams, E.S.; Konrad, T.R. Rural physician satisfaction: Its sources and relationship to retention. J. Rural. Health 1996, 12, 366-377. [CrossRef]

53. Phillips, J.; Hustedde, C.; Bjorkman, S.; Prasad, R.; Sola, O.; Wendling, A.; Bjorkman, K.; Paladine, H. Rural Women Family Physicians: Strategies for Successful Work-Life Balance. Ann. Fam. Med. 2016, 14, 244-251. [CrossRef] [PubMed]

54. Halvorsen, P.A.; Edwards, A.; Aaraas, I.J.; Aasland, O.G.; Kristiansen, I.S. What professional activities do general practitioners find most meaningful? Cross sectional survey of Norwegian general practitioners. BMC Fam. Pract. 2013, 14, 41. [CrossRef] [PubMed]

55. Droit-Volet, S.; Gil, S.; Martinelli, N.; Andant, N.; Clinchamps, M.; Parreira, L.; Rouffiac, K.; Dambrun, M.; Huguet, P.; Dubuis, B.; et al. Time and Covid-19 stress in the lockdown situation: Time free, «Dying» of boredom and sadness. PLoS ONE 2020, 15, e0236465. [CrossRef] [PubMed]

56. Ugbolue, U.C.; Duclos, M.; Urzeala, C.; Berthon, M.; Kulik, K.; Bota, A.; Thivel, D.; Bagheri, R.; Gu, Y.; Baker, J.S.; et al. An Assessment of the Novel COVISTRESS Questionnaire: COVID-19 Impact on Physical Activity, Sedentary Action and Psychological Emotion. J. Clin. Med. 2020, 9, 3352. [CrossRef] [PubMed]

57. Urzeala, C.; Duclos, M.; Chris Ugbolue, U.; Bota, A.; Berthon, M.; Kulik, K.; Thivel, D.; Bagheri, R.; Gu, Y.; Baker, J.S.; et al. COVID-19 lockdown consequences on body mass index and perceived fragility related to physical activity: A worldwide cohort study. Health Expect. 2021, 1-10. [CrossRef] 